\title{
Se necesitan artistas para decorar la Catedral Nueva de Plasencia. Lucas Mitata (c.1525-1598) y la traza para el retablo de la Resurrección (c.1592)
}

\author{
Vicente Méndez Hernán \\ Universidad de Extremadura \\ Juan Manuel Ramos Berrocoso \\ Instituto Teológico de Plasencia
}

RESUMEN:

La decisión que el obispo don fray Martín de Córdoba tomó en 1578 de poner fin a la construcción de la catedral nueva de Plasencia, dio lugar al inicio de una nueva etapa donde la ornamentación del templo recién inaugurado se convirtió en el principal objetivo para futuros prelados y canónigos. En este contexto se enmarca la traza inédita, y recientemente redescubierta en el Archivo Capitular, que Lucas Mitata hizo para la construcción de un retablo dedicado a la Resurrección de Cristo. Su presencia documentada en la ciudad de Alfonso VIII en 1592 nos ha permitido proponer este año como fecha posible para su ejecución. Se trata del segundo dibujo conservado de Mitata, anterior al que hizo para el entierro del obispo don Pedro García de Galarza en la catedral de Coria, y frente al cual, sin embargo, el placentino destaca por la calidad y el detalle con los que está ejecutado.

PALABRAS CLAVE:

Lucas Mitata; trazas; retablo Resurrección; catedral de Plasencia; siglo XVI.

\section{ABSTRACT:}

The decision which Bishop Martín de Córdoba took in 1578 to complete the construction of the new Cathedral of Plasencia gave rise to a new stage in which the ornamentation of the newly inaugurated place of worship became the main objective of future prelates and canons. This is the context of the hitherto unknown plan which has recently come to light in the Chapterhouse Archive and which was drawn up by Lucas Mitata for the construction of an altarpiece dedicated to the Resurrection of Christ. Its presence in the city of Alfonso VIII in 1592 is documented, which means that it may have been produced in that year. It is the second surviving drawing of Mitata and predates that which he made for the funeral of Bishop Pedro García de Galarza in the Cathedral of Coria, which is however of lower quality and less detailed than that of Plasencia.

\section{KEY WORDS:}

Lucas Mitata; plans; Resurrection altarpiece; cathedral of Plasencia; 16th century. 
1. Introducción. Análisis preliminar de la traza redescubierta en la Catedral de Plasencia

Las trazas que ejecutaron los artistas como paso previo a la rúbrica del contrato definitivo, siempre han sido un objeto de interés inusitado para la curiosidad de eruditos y coleccionistas, amén de haber estado expuestas a todos los factores de riesgo para la conservación del patrimonio documental. En la catedral de Plasencia tenemos constancia de los pagos que hizo el cabildo por las trazas que se presentaron durante los procesos de adjudicación de las obras de mayor envergadura, como el retablo mayor y el acuerdo que tomaron los canónigos en 1623 de dar "600 maravedís cada día a los maestros que hayan traido traças [...] y 50 rea-

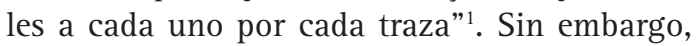
un escaso número de estos dibujos ha llegado a nuestros días, tal vez debido a su extravío, pérdida definitiva o sustracción en algún momento de la historia de esta centenaria institución. La traza que Lucas Mitata diseñó para un retablo dedicado a la Resurrección de Cristo (fig. 1), recientemente redescubierta y objeto del presente trabajo, estuvo sometida a la práctica totalidad de esos avatares: sufrió los efectos de la humedad, fue sustraída del archivo en fecha imprecisa y extraviada después de su devolución. El dibujo debía pertenecer al conjunto de trazas que fue presentado sub sigilum por el deán al cabildo en 19212: "El M. I. Sr. Deán dice que por persona que no le autorizó para dar su nombre le han sido entregados varios documentos que presenta y son planos de la catedral nueva y antigua y varios proyectos de las mismas de especial valor e importancia artísticos, para ser reintegrados al Ilmo. Cabildo [...]"3.

Sin que sepamos cuántos documentos integraban el precitado conjunto, diez dibujos fueron redescubiertos en 2008 por Juan Manuel Ramos, canónigo archivero, en una sala cerca-

MARTÍN GONZÁLEZ, Juan José, "Nuevas noticias sobre el retablo mayor de la Catedral de Plasencia (Cáceres)", en Boletín del Seminario de Estudios de Arte y Arqueología de Valladolid, vol. XL-XLI, Valladolid, 1975, p. 314.

RAMOS BERROCOSO, Juan Manuel, “Aportaciones documentales inéditas sobre la obra de la Catedral de Plasencia según las trazas de Manuel de Larra Churriguera en 1755", en Ars et Sapientia, vol. XXXIV, Cáceres, 2011, pp. 86-87.

3 Archivo de la Catedral de Plasencia (ACPl), Libro de Actas Capitulares n. ${ }^{\circ} 124$ (1920-1927), Cabildo del 8 de junio de 1921, p. 47. na a la antigua dependencia del Archivo Capitular. Y otros tres fueron localizados en agosto de 2009 por Tomás Sánchez y Julián Granado, sacristanes de la catedral, en una caja de madera de castaño dentro de uno de los armarios de la sacristía. Inmediatamente fueron inventariados por el citado archivero de manera provisional, asignando a cada cual un título, una breve descripción y, si era posible, su fecha y autor ${ }^{4}$.

La humedad que afectó a la traza de Lucas Mitata ocasionó el delicado estado de conservación que presenta; sus efectos son visibles en la pérdida que ha sufrido el dibujo, muy diluido o casi inexistente en la zona izquierda del retablo -evangelio-, así como en las manchas de agua que aparecen por todo el papel, y en la necesidad que surgió en un momento indeterminado de adherir el soporte original a otro más grueso para intentar mitigar los efectos del agua y preservar su conservación. Empero, nada de lo expuesto es óbice para advertir la mano de un escultor de extraordinaria capacidad como tracista, lo que refrenda las alusiones que de continuo se hacen en la documentación a esta habilidad de Mitata; y así lo comprobamos en las vistas principales del retablo, proyectado en planta y alzado con el uso de regla y compás. El dibujo es preciso, realizado con pluma y aguada sepia, y de una gran plasticidad gracias al sombreado, más intenso en el fondo de las hornacinas y tableros de los bancos que sustentan los dos cuerpos del retablo, sobre los que resaltan los dibujos de las tallas que habrían de poblar el conjunto.

La traza se completa con una serie de rótulos escritos en letra romana clásica o latina en su modalidad de capital cuadrada, para cuya ejecución se empleó el mismo tono sepia al utilizado en el resto del dibujo; sirven para identificar la "PLANTA", los tipos de columnas del primer y segundo nivel del retablo, "CORINTIA" y "COMPOSITA" respectivamente, así como la "PEAÑA" del remate. Como rasgos singulares de la escritura citemos el punto que llevan las íes por influencia de la letra humanística redonda o formada, y la palabra "PEAÑA", sustantivo que Sebastián de Covarrubias recogía en su diccionario de 1611 escrito con la letra

\footnotetext{
$\mathrm{ACPl}$ Inventario provisional de trazas antiguas [sin signatura]. Tras enviar este artículo a la revista para su evaluación, ha aparecido otra traza: el sistema de llaves y cerraduras de un cofre fechado en 3/8/1707. Este extraordinario ingenio aún se conserva, pero sin las llaves que ahora pueden ser reproducidas.
} 


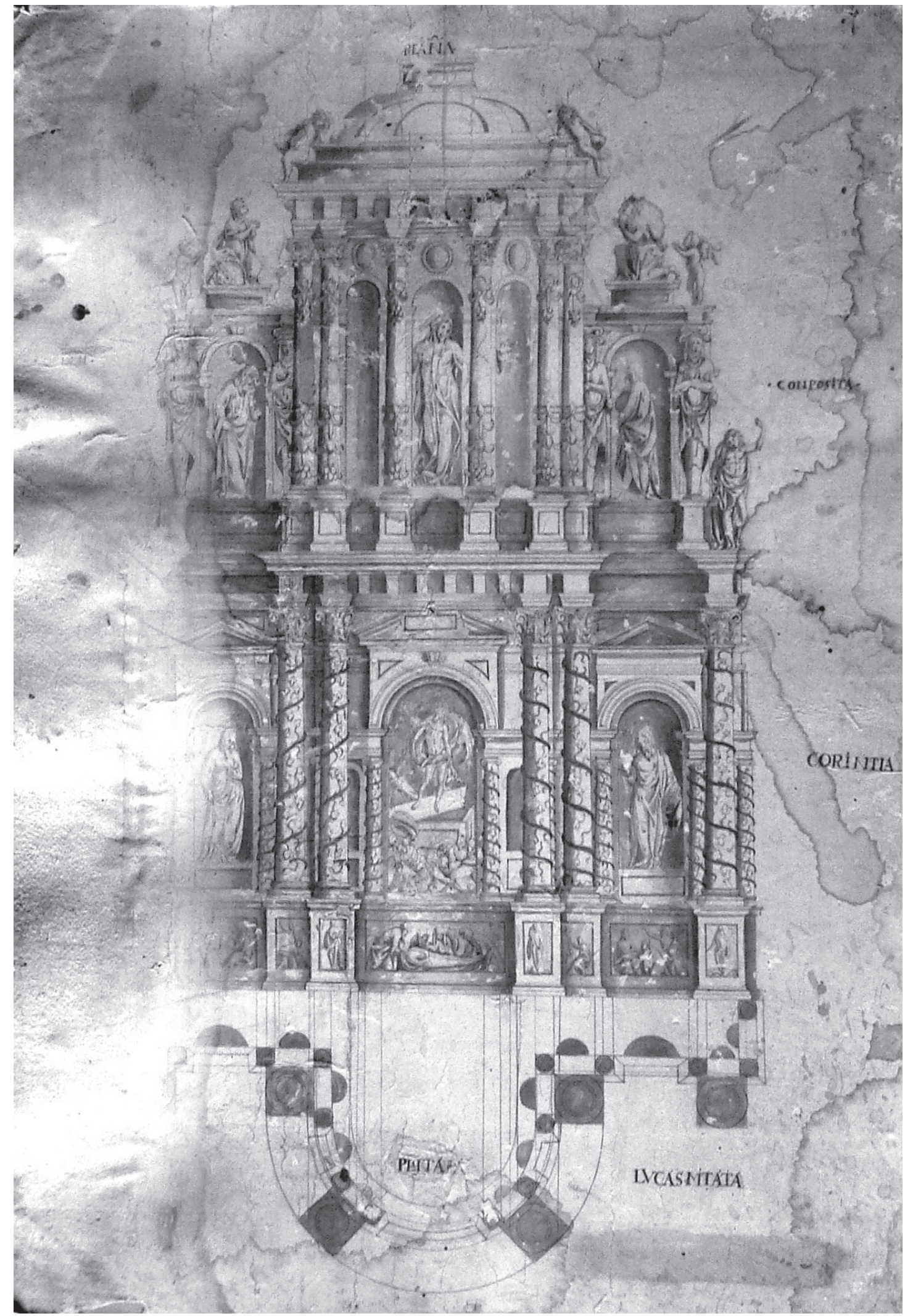

Fig. 1. Lucas Mitata, Traza para el retablo de la Resurrección, c.1592. Plasencia, ACPl, sin signatura. 
"ñ"5. La escritura se corresponde plenamente con las tendencias gráficas del siglo XVI; y, dada la perfección de las letras, es muy probable que su ejecución fuera encomendada a un buen calígrafo de los que entonces laboraban en Plasencia ${ }^{6}$, lo cual, por otro lado, era algo habitual en la época.

Se añade un letrero con el nombre del autor, "LVCAS MITATA", situado en la parte inferior derecha de la traza. El haber optado por el tipo de letra señalada constituye un aspecto más para advertir el cuidado que el artista puso en la ejecución del dibujo, al tratarse de un trabajo de presentación, que finalmente no se llevaría a cabo. En el corpus artístico de Lucas Mitata, la traza de Plasencia es la primera que se ha conservado con el diseño de un retablo y la segunda que nos ha llegado de su mano, anterior a los modelos que firmó el 4 de mayo de 1595 con el maestro de arquitectura Juan Bravo, para realizar el sepulcro del obispo don Pedro García de Galarza (1578-1603) en la catedral de Coria ${ }^{7}$; en este caso, el dibujo es más lineal y carece de la calidad y detalle que tiene el placentino.

\section{El obispo d. Juan Ochoa y Salazar y la ornamentación de la Catedral Nueva}

La histórica decisión que el obispo don fray Martín de Córdoba (1574-1578) tomó el último año de su pontificado al frente de la diócesis de Plasencia, ordenando el traslado definitivo del Santísimo Sacramento desde la "iglesia Vieja" a la catedral nueva para su inauguración el día del Corpus de $1578^{8}$, obligó a dar por terminadas las obras de esta fábrica arquitectónica estando aún inconclusa, y a iniciar un período donde los trabajos de ornamentación del nuevo templo se convirtieron en el principal

5 COVARRUBIAS OROZCO, Sebastián de, Tesoro de la Lengva Castellana, o Española, Luis Sánchez, Madrid, 1611, p. $581 \mathrm{v}$.

6 FERNÁNDEZ SERRANO, Francisco, "Artistas del libro litúrgico en Plasencia (Siglos XV-XVII)”, en Boletín del Seminario de Estudios de Arte y Arqueología de Valladolid, vol. XVI, fascs. LII-LIV, Valladolid, 1950, pp. 60-67.

7 SÁNCHEZ LOMBA, Francisco M., "El escultor Lucas Mitata y el Obispo Galarza en la Catedral de Coria”, en Norba-Arte, vol. IX, Cáceres, 1989, pp. 46-47.

8 FERNÁNDEZ, Fray Alonso, Historia y Anales de la Civdad y Obispado de Plasencia, Iuan Gonçalez, Madrid, 1627, p. 244; GONZÁLEZ CUESTA, Francisco, Los Obispos de Plasencia, Caja de Extremadura, Cáceres, 2013, 2 tomos, t. I, pp. 313-315. objeto de preocupación para futuros prelados y canónigos. Las obras conducentes a tal fin se sucedieron desde comienzos de la década de 1580. El proyecto del trascoro (1581), las vidrieras de la catedral (retomadas a finales de 1582), o el ornato del altar mayor y el nuevo de las reliquias $(1584)^{9}$, fueron los precedentes para la gran etapa de expansión decorativa que tendría lugar -como bien recordaba González Cuesta- bajo el pontificado de don Juan Ochoa y Salazar (1587-1594) ${ }^{10}$. Durante este episcopado se profundizó en el trabajo de las vidrieras, y se insistió en la decoración de la capilla situada en el brazo del crucero por el costado de la epístola -junto a la puerta de la sacristía-: en 1584 se había ubicado en ella el citado altar de las reliquias, obra del aparejador Juan Álvarez, y en 1593 dicho altar se eligió para situar la escultura de la Virgen del Tránsito que ese mismo año llegaría a Plasencia ${ }^{11}$.

La capilla del evangelio también debió ser objeto de un proyecto ornamental sujeto a un programa iconográfico más amplio y diseñado para los brazos del crucero en su conjunto. Esta idea de homogeneidad para los espacios adyacentes al arco triunfal se constata con los "dos grandes relicarios" que el obispo don Sancho Dávila y Toledo (1622-1625) ordenaría construir en las "dos naves Colaterales al altar Mayor" ${ }^{12}$; y con los dos retablos barrocos que se hicieron en la primera mitad del siglo XVIII para sustituirlos: el churrigueresco de la Virgen del Tránsito (1724 y 1725) y el de las reliquias (1746-1748), en cuyo contrato se estipuló además que habría de ser simétrico al mariano ${ }^{13}$. Si tenemos en cuenta este planteamiento, y el hecho de haber destinado la capilla del crucero por la epístola al entierro de María, no es desacertado pensar que el retablo dedicado a

BENAVIDES CHECA, José, Prelados placentinos. Notas para sus biografías y para la Historia documental de la Santa Iglesia Catedral y Ciudad de Plasencia, Ayuntamiento de Plasencia, Plasencia, 1999 [1907¹], pp. 197198.

10 GONZÁLEZ CUESTA, Francisco, Los Obispos de Plasencia..., opus cit., t. I, pp. 335-336.

11 MÉNDEZ HERNÁN, Vicente, "Aportaciones documentales en torno a los retablos de la Virgen del Tránsito y de las reliquias de la Catedral de Plasencia", en Revista de Estudios Extremeños, vol. LVI, n. ${ }^{\circ}$ 2, Badajoz, 2000, p. 416.

12 FERNÁNDEZ, Fray Alonso, Historia y Anales..., opus cit., p. 323; MÉNDEZ HERNÁN, Vicente, Aportaciones documentales..., opus cit., pp. 417-418.

13 MÉNDEZ HERNÁN, Vicente, Aportaciones documentales..., opus cit., pp. 408-503, passim. 
la Resurrección de Cristo se hubiera ideado para ornamentar el lado contrario, esto es, la capilla del crucero por el evangelio; y que todo este programa iconográfico se hubiera concebido durante el pontificado de Ochoa y Salazar. Coadyuvan a esta hipótesis varios factores: en primer lugar, la presencia de Lucas Mitata en la ciudad de Plasencia en 1592 -según veremos-, lo que nos permite fechar la traza dentro del pontificado que nos ocupa; el segundo factor es el hecho de no haber más espacios disponibles en la catedral nueva donde situar un retablo como el diseñado en la traza, el cual, por otra parte, no podía estar destinado a la "iglesia Vieja” porque estaba sin culto desde 1578; y, por último, cabe pensar que un retablo con la Resurrección de Cristo estuviera destinado a ocupar un espacio preeminente dentro del templo.

De este modo, el crucero catedralicio quedaba consagrado a la Resurrección de Cristo y al entierro de María ${ }^{14}$, quien, según los apócrifos asuncionistas $^{15}$, resucitó a los tres días al igual que su Hijo. El tema de la Resurrección de la Virgen había desaparecido a finales del siglo XIII tras ser reemplazado por el de la Asunción ${ }^{16}$, de ahí que en la epístola se optara por representar su entierro, y la Asunción, a la que está consagrada la catedral, se reservara para el presbiterio y el futuro retablo mayor, de cuya ejecución se haría cargo Gregorio Fernández (1576-1636) en mayo de $1625^{17}$, después de ha-

14 Las reliquias que estaban situadas en la capilla de la epístola procedían de la prelatura anterior (RAMOS BERROCOSO, Juan Manuel, "Iconografía e iconología del Retablo Mayor de la Catedral de Plasencia. Una mirada teológica sobre el arte", en Toletana, vol. XXVII, Toledo, 2012, p. 210) y, en cualquier caso, no entraban en contradicción con este nuevo planteamiento, al ser la Virgen y los santos los intercesores entre Dios y los hombres.

15 Para conocer esta literatura véase, v. gr., GONZÁLEZ CASADO, Pilar, "Los apócrifos asuncionistas", en $\mathrm{Fa}$ cies Domini: revista alicantina de estudios teológicos, vol. II, Alicante, 2010, pp. 175-190. Y una edición de garantía en DE SANTOS OTERO, Aurelio, Los Evangelios Apócrifos. Edición crítica y bilingüe, BAC, Madrid, 2017 ${ }^{14}$, pp. 567-653.

16 RÉAU, Louis, Iconografía del arte cristiano. Iconografía de la Biblia, t. 1, vol. 2, Nuevo Testamento, Ediciones del Serbal, Madrid, 1996 [1957¹], pp. 637-638.

17 MARTÍN GONZÁLEZ, Juan José, Nuevas noticias..., opus cit., pp. 302-304, 311-313; MÉNDEZ HERNÁN, Vicente, "El Testamento de Gregorio Fernández y el proceso de culminación del retablo mayor de la catedral de Plasencia”, en Archivo Español de Arte, vol. LXXXV, n. ${ }^{\circ}$ 339, Madrid, 2012, pp. 273-279; RAMOS BERROCOSO, Juan Manuel, Iconografía e iconología..., opus cit., pp. 216-226. ber "estado la iglesia sin retablo doscientos, ó trescientos años"18. Por otro lado, el tema de la Resurrección de Cristo contaba con un precedente singular en la catedral placentina, donde se conserva un fino relieve de alabastro, de finales del siglo XV, con la efigie de Jesús sentado sobre el sepulcro; José Ramón Mélida lo vio entre 1914 y 1918 en la antigua sala capitular -o capilla de San Pablo- ${ }^{19}$, y hoy se expone en el museo catedralicio.

\section{El retablo de la Resurrección de Lucas Mitata}

El espacio temporal comprendido entre 1588, año en el que se tomó la decisión de encargar la talla de la Virgen del Tránsito, y el momento de su llegada a la ciudad en $1593^{20}$, coincide con la prelatura de Ochoa y Salazar y engloba el año 1592 en el que tenemos documentada la presencia de Lucas Mitata en la ciudad de Alfonso VIII. El cabildo debió aprovechar, si no propiciar, este viaje para encargarle la traza que nos ocupa y ultimar así el programa iconográfico ideado y madurado desde que se decidiera celebrar la fiesta de la Asunción de 1588 con el encargo de una nueva escultura.

La estancia de Mitata en la ciudad se enmarca en el contexto de la traza y modelo que había contratado en 1592 para el pabellón de la custodia de la catedral de Coria, hoy desaparecido. La ejecución material de la obra se ajustó con Valentín Romero, oficial de arquitectura y vecino de Plasencia, según consta en la carta de obligación que escrituró el 21 de mayo de 1592 ante el escribano placentino Gonzalo Jiménez ${ }^{21}$, y, lo más interesante para

${ }_{18}$ Así lo recordaba el licenciado Juan M. Cabeza Leal en la carta que remitió al cabildo en marzo de 1629 para aconsejarle sobre el modo de tratar con el artista avecindado en la ciudad del Pisuerga: PONZ, Antonio, Viage de España, Joachin Ibarra, Madrid, t. VII, $1778^{1}$ y $1784^{2}$, p. 103.

19 MÉLIDA ALINARI, José Ramón, Catálogo Monumental de España. Provincia de Cáceres, Ministerio de Instrucción Pública y Bellas Artes, 3 tomos, Madrid, 1924, t. II, p. 300; t. III, fig. 305; MUÑOZ COSME, Alfonso, "Catálogos e inventarios del Patrimonio en España", en El Catálogo Monumental de España (1900-1961). Investigación, restauración y difusión, CSIC, Madrid, 2012, p. 30.

20 MÉNDEZ HERNÁN, Vicente, Aportaciones documentales..., opus cit., pp. 416 y 476.

21 MARTÍN NIETO, Dionisio, "Luis de Morales y Lucas Mitata en el Sacro Convento de la Orden de Alcánta- 
nosotros, con la presencia del propio Mitata entre los testigos instrumentales ${ }^{22}$, un dato que hasta ahora había pasado desapercibido para la historiografía artística. El viaje del escultor no era necesario para la rúbrica del documento porque el cabildo cauriense contaba con el clérigo Juan Sánchez, capellán de la catedral de Coria, como delegado para escriturar el contrato con Valentín Romero ${ }^{23}$, lo que tuvo lugar el 1 de junio de ese mismo año ${ }^{24}$. Por otro lado, el nombre de Mitata no vuelve a figurar en los protocolos notariales de la ciudad, y en ningún otro documento relacionado con Plasencia, al menos hasta la fecha y que sepamos, lo que nos permite conjeturar que la traza debió realizarse en los días siguientes a la firma de la precitada escritura de obligación.

En la elección del escultor debió jugar un papel primordial la fama que ya acumulaba para esas fechas; recordemos que en 1562 los encargados de concertar el Crucificado para el hospital mirobrigense de la Pasión -en cuya iglesia se conserva- se refirieron a él como "un oficial muy bueno" 25 . Y esa fama fue la que llevó al conocido maestro en humanidades Juan López de Hoyos (Madrid, 1511-1583) a citarlo hasta en tres ocasiones, al igual que hizo con Pompeo Leoni, en el libro que publicó en 1572

ra. Nuevas aportaciones documentales", en Revista de Estudios Extremeños, vol. LVIII, n. ${ }^{\circ}$ 1, Badajoz, 2002, p. 59, y nota 78. La referencia documental: Archivo Histórico Provincial, Cáceres (AHPCC), Protocolos Notariales (PN), Plasencia, Gonzalo Jiménez, leg. 1295, s.f., 21 de mayo de 1592.

22 AHPCC, PN, Plasencia, Gonzalo Jiménez, leg. 1295, s.f., 21 de mayo de 1592.

23 Ibidem, 29 de mayo de 1592, traslado del poder otorgado ante el escribano de Coria Francisco González. En la actualidad no se conservan los protocolos de las escribanías caurienses correspondientes al siglo XVI.

24 PÍRIZ PÉREZ, Emilio, "El escultor Lucas Mitata", en Boletín del Seminario de Estudios de Arte y Arqueología de Valladolid, vol. XLIII, Valladolid, 1977, pp. 244, 248. La referencia documental: AHPCC, PN, Plasencia, Gonzalo Jiménez, leg. 1295, s.f., 1 de junio de 1592. Píriz Pérez confundió al delegado del cabildo con el escribano placentino Gonzalo Jiménez, señalando como notario al precitado Juan Sánchez.

25 HERNÁNDEZ VEGAS, Mateo, Ciudad Rodrigo. La Catedral y la ciudad, 2 tomos, Excmo. Cabildo de la Catedral de Ciudad Rodrigo, Salamanca, 1982 (ed. facsímil de la primera de 1935), t. II, pp. 36-37 (la cita literal en p. 37); PÍRIZ PÉREZ, Emilio, El escultor Lucas Mitata, opus cit., p. 240; REDONDO CANTERA, M. ${ }^{\text {a José, }}$ "Lucas Mitata y la escultura funeraria de la catedral de Ciudad Rodrigo", en La Catedral de Ciudad Rodrigo a través de los siglos. Visiones y revisiones, Diputación de Salamanca, Caja Duero y Diócesis de Ciudad Rodrigo, Salamanca, 2006, p. 454. con la descripción de la entrada en Madrid que la reina Ana de Austria había protagonizado en $1570^{26}$. Casualidad o no, recordemos que López de Hoyos era capellán de la capilla que el obispo placentino don Gutierre de Vargas Carvajal (1524-1559) había dotado para su entierro en la iglesia madrileña de San Andrés ${ }^{27}$, cuyo patronazgo ejercía en 1572 don Francisco de Vargas Manrique, sobrino carnal del prelado ${ }^{28}$. Se desprende de lo expuesto el vínculo que López de Hoyos tenía con los Vargas madrileños y los Carvajales extremeños, y nos aporta un aspecto más para acercarnos al contexto sociológico del que emanó el viaje que Mitata hizo a Plasencia en 1592, tras ser convocado en respuesta a su más que demostrada nombradía. De hecho, el haber incluido su nombre en la traza, escrito en letra romana clásica, es un claro indicio de la estima y reconocimiento que él mismo había asumido que tenía.

La sucinta descripción que López de Hoyos hizo de Mitata al referirse a él como un "raro hombre en su professión y facultad" 29 , tiene su refrendo en la singularidad de la traza que nos ocupa, puesto que no existe parangón en el contexto artístico extremeño de la segunda mitad del siglo XVI. Se unen la precisión en el dibujo y el sombreado, con el que logra otorgar plasticidad al diseño; y el uso de motivos de raigambre manierista para decorar una estructura donde utiliza elementos de filiación clasicista con cierta libertad y carácter innovador, según constatamos a partir del sarmiento helicoide que retalla en la caña de las columnas del primer cuerpo, o del impulso vertical que otorga a la calle central para romper la calma horizontalista más propia del clasicismo.

Lucas Mitata trazó un retablo de dos cuerpos recorridos por tres calles, y ático. En función de

26 LÓPEZ DE HOYOS, Juan, Real apparato, y sumptuoso recebimiento con que Madrid (como casa y morada de su M.) rescibió a la Serenissima reyna D. Ana de Austria..., Iuan Gracián, Madrid, 1572. Citamos por la edición de SIMÓN DÍAZ, José, Fuentes para la Historia de Madrid y su provincia, t. I: Textos impresos de los siglos XVI y XVII, Instituto de Estudios Madrileños, Madrid, 1964, pp. 62, 89 y 114 (Mitata); y pp. 62, 95 y 107 (Leoni).

27 GONZÁLEZ PALENCIA, Ángel, "El testamento de Juan López de Hoyos, maestro de Cervantes", en Revista de Archivos, Bibliotecas y Museos, vol. XLI, n. ${ }^{\text {os }} 10-12$, Madrid, 1920, p. 595.

28 LÓPEZ DE HOYOS, Juan, Real apparato..., opus cit., p. 58.

${ }_{29} \quad$ Ibídem, p. 89. 
la planta incluida en el dibujo, el modelo que plasmó en el diseño se resuelve con un profundo nicho central cupulado, flanqueado con dos calles laterales de planta recta. Entre los precedentes para este tipo de composición planimétrica, cabe recordar el retablo que Alonso Berruguete ejecutó para el convento vallisoletano de San Benito el Real entre 1526 y 1532, utilizando para ello un diseño donde es evidente la relación con obras de Bramante o Antonio da Sangallo el Joven ${ }^{30}$; y el que hizo Juan de Juni para la capilla funeraria de fray Antonio de Guevara, obispo de Mondoñedo, en el desaparecido convento de San Francisco ubicado también en la ciudad del Pisuerga, y del que solo se conserva el Entierro de Cristo (c.15421543) en el Museo Nacional de Escultura ${ }^{31}$. Sin embargo, y aun teniendo en cuenta que esta serie de precedentes apuntan hacia la zona castellana en la que Mitata debió formarse en el entorno leonés ${ }^{32}$ o directamente con Juan de Juni ${ }^{33}$-, no fueron tanto estas obras como los grabados que allí conoció los que le sirvieron de modelo para la traza placentina. Ésta guarda relación con la estampa que el pintor, editor y grabador Hieronymus Cock (Amberes, 1507/1510-Roma, 1570) publicó en 1563 con el Cenotafio o Mausoleo de un noble (fig. 2), integrante de una serie de veintisiete láminas realizadas sobre el modelo original que Hans Vredeman de Vries (Leeuwarden, Países Bajos, 1527-Amberes, 1609) había creado ese mismo año con el título Coenotaphiorum ${ }^{34}$. Nos inte-

30 ARIAS MARTÍNEZ, Manuel, Alonso Berruguete, Prometeo de la escultura, Diputación Provincial de Palencia, Vizcaya, 2011, pp. 97-116. Sobre la influencia de este retablo, vid. etiam PARRADO DEL OLMO, Jesús María, "La huella del retablo de San Benito de Alonso Berruguete en el obispado de Palencia”, en Laboratorio de Arte, n. ${ }^{\circ}$ 29, Sevilla, 2017, pp. 107-120.

31 MARTÍN GONZÁLEZ, Juan José, Juan de Juni. Vida y obra, Publicación del Patronato Nacional de Museos, Madrid, 1974, pp. 142-158; FERNÁNDEZ DEL HOYO, $\mathrm{M}^{\mathrm{a}}$ Antonia. Juan de Juni, escultor, Universidad de Valladolid, Valladolid, 2012, pp. 157-162.

32 REBOLLAR ANTÚNEZ, Alba, Lucas Mitata. Un escultor singular, h.1525-1598, Ediciones Universidad de Valladolid, Valladolid, 2016, p. 32.

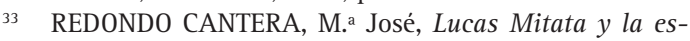
cultura funeraria..., opus cit., p. 455.

34 GONZÁlEZ DE ZÁRATE, Jesús María (ed.), Real Colección de Estampas de San Lorenzo de El Escorial, Ephialte y Patrimonio Nacional, Vitoria-Gasteiz, 1993, t. II, pp. 145, y 177, estampa 15.21.(605); HOLLSTEIN, Friedrich Wilhelm Heinrich/FUHRING, Peter/LUIJTEN, Ger, Dutch and Flemish etchings, engravings and woodcuts, 1450-1700, vol. XLVII: Vredeman de Vries, resa el segundo cuerpo del mausoleo, resuelto con un nicho central cupulado bajo el que se yergue la figura del Resucitado; se añaden dos hornacinas laterales y atlantes en los extremos, y todo ello de un modo muy similar al planteamiento que Mitata diseñó en el segundo nivel de la traza que nos ocupa. Recordemos que $\mathrm{H}$. Cock fue uno de los grabadores e impresores más destacados de Amberes y -en palabras de González de Zárate- el editor más ecléctico de la época por los distintos estilos que trabajó, como el italianismo clásico o el manierismo de Fontainebleau ${ }^{35}$. Recordemos también la relación entre Vredeman de Vries y los modelos de la citada Escuela francesa de pintura, así como el vínculo que Arias Martínez advirtió entre dichos modelos y la obra de Juan de Juni en San Marcos de León; una relación con Fontainebleau que el artista de Joigny intensificó posteriormente, bien por los contactos que seguía manteniendo con su país natal o por un viaje esporádico ${ }^{36}$. En definitiva, un amplio marco de relaciones artísticas en el que Lucas Mitata pudo haber conocido el citado grabado o similares, y en el que también se inscribe la solución cupulada del remate, de carácter innovador para la zona extremeña tanto en lo que respecta a la arquitectura lignaria como pétrea.

Ecos junianos se advierten en algunos elementos arquitectónicos del primer nivel de nuestro retablo. El distinto tamaño de las hornacinas dispuestas en la calle central, o el de las columnas que estructuran el alzado frente a las que sustentan los arcos de los nichos en segundo plano, y aún sin que ello suponga romper la verticalidad de los soportes principales, hacen inevitable recordar los retablos catedralicios de Valladolid -procedente de la iglesia de Santa María de La Antigua (1551-1562)- o de El Burgo de Osma (1550-1554), y la inventiva, netamente manierista, con la que el artista francés los diseñó.

Por otro lado, la decoración que Mitata emplea para la caña de las columnas del primer cuerpo, con tallos vegetales recorriendo el fuste de forma helicoidal, recuerda las dos

Part I, 1555-1571, Sound and Vision Interactive, Rotterdam, 1997, pp. 129, y 146, estampa 157.

35 GONZÁLEZ DE ZÁRATE, Jesús María (ed.), Real Colección de Estampas..., opus cit., t. II, p. 143

36 ARIAS MARTÍNEZ, Manuel, "Revisando a Juan de Juni en San Marcos de León. Fuentes y Modelos”, en Boletín de la Real Academia de Bellas Artes de la Purísima Concepción, vol. 43, Valladolid, 2008, pp. 15, 29, 30. 


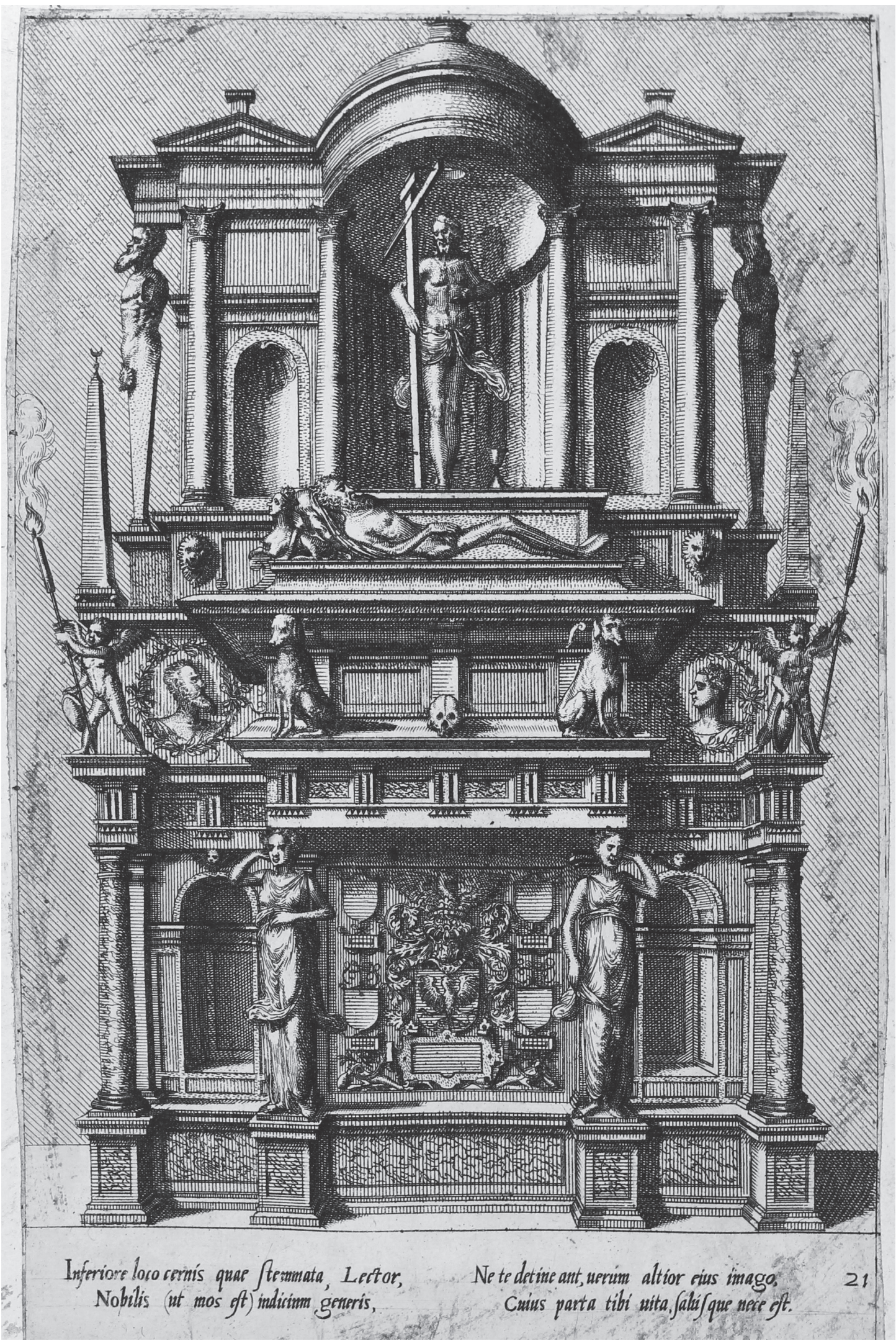

Fig. 2. Hieronymus Cock, Cenotafio o Mausoleo de un noble, según el modelo de Hans Vredeman de Vries para la serie Coenotaphiorum, 1563. Real Biblioteca del Monasterio de El Escorial, Patrimonio Nacional, sign. 28-II-24, fol. 107. 
columnas gigantes que Juni retalló con el árbol de Jesé para el retablo oxomense; pero en nuestro caso se trata de un motivo decorativo más, utilizado de un modo parecido a la tercera variante que el abulense Gerónimo Hernández había introducido en el ornato retallado para las columnas del retablo de San Mateo en Lucena (Córdoba) (1570-1580), donde la caña se decora con un sarmiento vegetal que recorre el fuste helicoidalmente y del que parten zarcillos espirales. Como señala Palomero Páramo, el modelo no podía ser más interesante al preludiar las fórmulas entorchadas y salomónicas ${ }^{37}$, y evidencia el talante innovador de Lucas Mitata. Nuestro artista pudo conocer este singular motivo a partir de estampas como la que González de Zárate le atribuye a León Davent con el tema de Cristo, Pedro y Pablo insertos en las iniciales del nombre de Jesús con columnas y sarmientos que las rodean, siendo Davent uno de los artistas de la Escuela de Fontainebleau activo hacia $1540^{38}$. Y no olvidemos que Juan de Arfe y Villafañe también había recogido este tipo de ornato en 1585 al tratar del orden compuesto en su De Varia Commesvracion ${ }^{39}$.

Idéntico sentido decorativo persigue el modelo de columna "COMPOSITA" diseñada para el segundo cuerpo del retablo, claramente inspirado en el mismo tipo de soporte con el que Vredeman de Vries cerró su tratado de arquitectura (fig. 3) ${ }^{40}$, sobre todo en lo que respecta a los medallones ovales y entelados retallados bajo el collarino y el tercio inferior del fuste. Lo mismo sucede con los estípites en forma de atlantes que flanquean las hor-

37 PALOMERO PÁRAMO, Jesús Miguel, El retablo sevillano del Renacimiento: análisis y evolución (15601629), Diputación Provincial de Sevilla, Sevilla, 1983, pp. 92, 261-264.

38 GONZÁLEZ DE ZÁRATE, Jesús María (ed.), Real Colección de Estampas de San Lorenzo de El Escorial, Ephialte y Patrimonio Nacional, Vitoria-Gasteiz, 1993, t. III, pp. 155, y 159, estampa 6.(1071); ZERNER, Henri, The School of Fontainebleau. Etchings and Engravings, Thames and Hudson, London, 1969, pp. 21-25.

39 ARPHE Y VILLAFAÑE, Ioan de, De Varia Commensvracion para la Escvlptvra y Architectura, Andrea Pescioni y Iuan de León, Sevilla, 1585, Lib. IV, cap. V, f. 19 r.

40 VREDEMAN DE VRIES, Hans (1577): Architectvra..., Geerhardt de Jode/Gérard Smits, Antwerpen, 1577, f. 115 r.; HOLLSTEIN, Friedrich Wilhelm Heinrich/ FUHRING, Peter/LUIJTEN, Ger, Dutch and Flemish etchings, engravings and woodcuts, 1450-1700, vol. XLVIII: Vredeman de Vries, Part II, 1572-1630, Sound and Vision Interactive, Rotterdam, 1997, pp. 61, y 85, estampa 431. nacinas laterales del segundo cuerpo (fig. 4), muy parecidos al soporte antropomorfo que Jean Mignon, activo entre 1537/40 y 1552 y uno de los grabadores más importantes de la Escuela de Fontainebleau, dedicó al dios Silvano ${ }^{41}$ a partir de los dibujos originales de Polidoro da Caravaggio $(+1543)$ para una serie de detalles arquitectónicos ${ }^{42}$; asimismo, y al igual que Jean Mignon, Giulio di Antonio Bonasone (Bolonia, c.1498-Roma, 1580) también grabó el citado término con la forma del dios Silvano, aunque, a diferencia de Mignon, lo efigió junto a una ninfa en una sola estampa (fig. 5) ${ }^{43}$. Por otro lado, recordemos que Serlio había señalado el orden compuesto en relación a los arcos de triunfo, el triunfo de Cristo en nuestro caso, y que dicho orden seguía al corintio en el alzado de las construcciones $^{44}$. Lo mismo sucede con el orden colosal que nuestro escultor diseñó en el primer cuerpo del retablo, recogido también en los tratados de Serlio, y de Palladio en menor medida, así como en distintos ejemplos de la zona castellana vinculados con la retablística de Juan de Juni y Gaspar Becerra ${ }^{45}$.

La influencia juniana también se advierte en el diseño de la escultura situada en el cornisamento del primer cuerpo por la epístola, a plomo con las columnas laterales; Mitata sigue fielmente el modelo humano, la torsión del cuerpo y el contraposto de la escultura dedicada a la Sinagoga y alusiva al Antiguo Testamento, que Juni situó en el mismo sitio del

${ }_{41}$ ZERNER, Henri, The School of Fontainebleau..., opus cit., pp. 26-30; estampa reproducida con la referencia J.M.26

42 MASSARI, Stefania, Giulio Bonasone, Catalogo della mostra, Ministerio per i Beni Culturali e Ambientali/ Instituto Nazionale per la Grafica, Roma 1983, 2 volumini, n. ${ }^{\circ} 75$ a.

43 Ibidem. Ejemplares de esta estampa se conservan en la Real Biblioteca de El Escorial: GONZÁLEZ DE ZÁRATE, Jesús María (ed.), Real Colección de Estampas de San Lorenzo de El Escorial, Ephialte y Patrimonio Nacional, Vitoria-Gasteiz, 1992, t. I, p. 205, estampa 24.(316); en el Museum of Fine Arts de Budapest (n. ${ }^{\circ}$ de inventario 6469); y en el Museo Británico de Londres, aunque en este caso las dos figuras, el dios Silvano y la ninfa, se han separado en dos estampas (n. ${ }^{\text {s }}$ de inventario H,5.195 y H,5.196, respectivamente).

44 SERLIO, Sebastián, Libro Qvarto de Architectvra, Iuan de Ayala, Toledo, 1552 [1537¹], Lib. IV, cap. IX, ff. LXIII v, LXIIII v.

45 MUÑOZ JIMÉNEZ, José Miguel, "El orden colosal en el retablo español del Renacimiento", en Boletín del Seminario de Estudios de Arte y Arqueología de la Universidad de Valladolid, vol. LXI, Valladolid, 1995, pp. 337-346. 


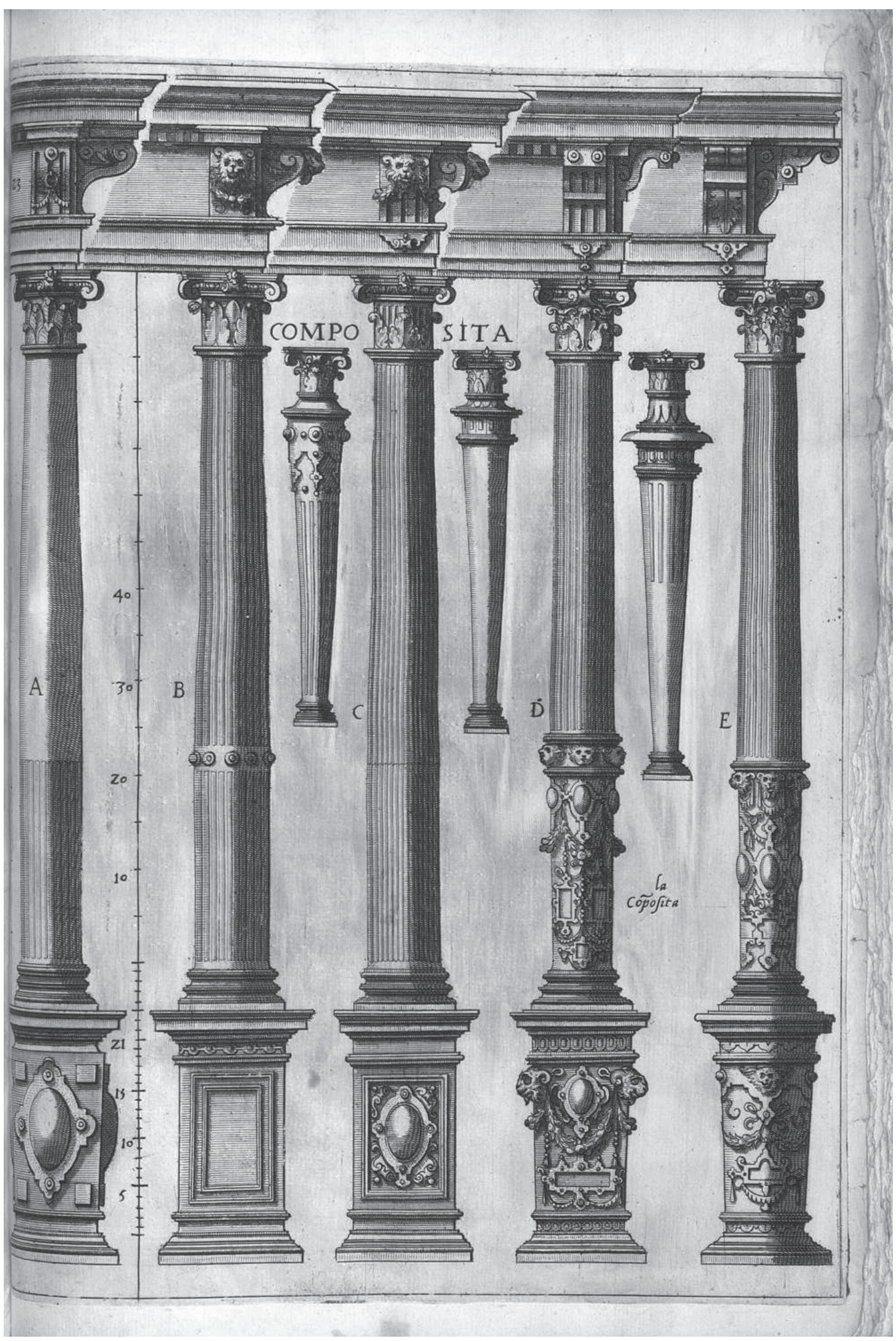

Fig. 3. Hans Vredeman de Vries, "Oorden Composita”, 1577, grabado procedente de la obra Architectvra... Antwerpen: Geerhardt de Jode; Gérard Smits, f. 115r. 


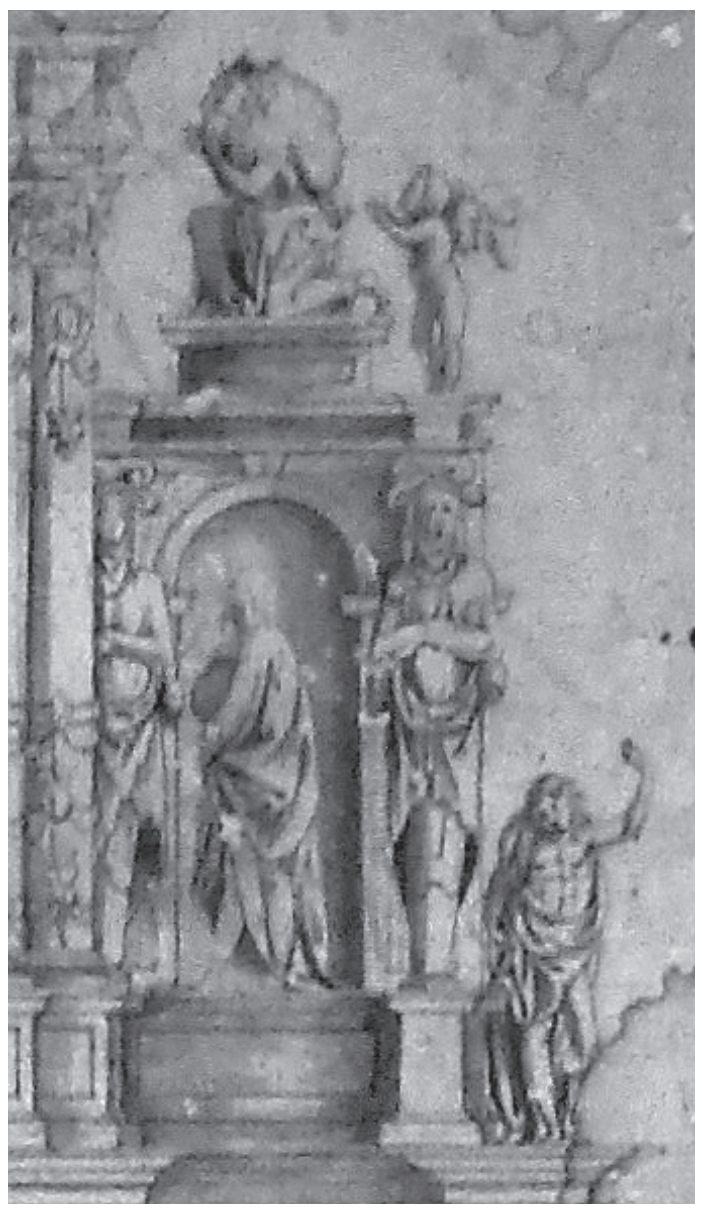

Fig. 4. Lucas Mitata, Traza para el retablo de la Resurrección, c.1592. Plasencia, ACPl, sin signatura. Detalle del ático por la epistola.

retablo de Burgo de Osma ${ }^{46}$. Una vez más se ponen de manifiesto las "fuertes evocaciones del maestro francés”, que Redondo Cantera advertía en distintos elementos del retablo mayor que el artista concertó antes de 1575 para la iglesia de San Juan Bautista, en Fuenteguinaldo (Salamanca), llegando a sugerir incluso una hipotética formación de nuestro escultor con el maestro de Joigny hasta mediados de la década de $1550^{47}$. De hecho, las esculturas situadas en los laterales del ático de este retablo también guardan relación con la citada figura de la traza placentina.

Por otro lado, Lucas Mitata no era ajeno a la proyección italiana ${ }^{48}$, y en ella debió pro-

46 MARTÍN GONZÁLEZ, Juan José, Juan de Juni..., opus cit., p. 211 y fig. 180.

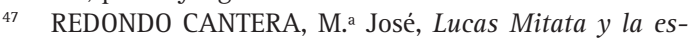
cultura funeraria..., opus cit., p. 455.

48 REBOLLAR ANTÚNEZ, Alba, Lucas Mitata..., opus cit., pp. 42-56, passim.

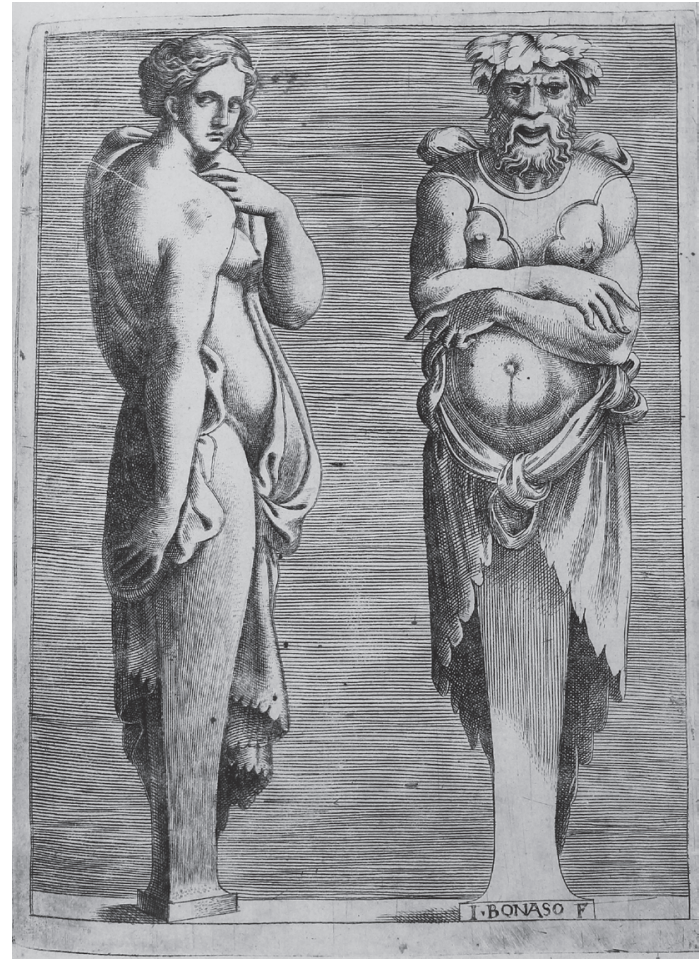

Fig. 5. Giulio di Antonio Bonasone, Términos del dios Silvano y de una ninfa, sobre un dibujo original de Polidoro da Caravaggio, c.1545-1550. Real Biblioteca del Monasterio de El Escorial, Patrimonio Nacional, sign. 28-II-9, fol. 159.

fundizar gracias a su presencia en el elenco de artistas encargados de las arquitecturas efímeras con las que se recibió en Madrid a la cuarta esposa de Felipe II en 1570, donde trabajó junto a Pompeo Leoni o Simón de Baena, escultor y frecuente colaborador de Gaspar Becerra ${ }^{49}$. Como señala Rebollar Antúnez, nuestro artista debió contemplar en Madrid el desaparecido retablo mayor de las Descalzas Reales, en cuya ejecución definitiva Becerra introdujo algunas variantes con respecto a la traza de 1563 -hoy conservada en la Biblioteca Nacional de España-, según se desprende del grabado que Jesús Avrial publicó en 1839 con la imagen del retablo veintitrés años antes de su incendio ${ }^{50}$. Tanto en la traza como en el retablo que se ejecutó,

49 Ibidem, p. 47, y nota 92; REDÍN MICHAUS, Gonzalo, Pedro Rubiales, Gaspar Becerra y los pintores españoles en Roma (1527-1600), CSIC, Madrid, 2007, p. 250.

50 FABRE, F., "Madrid artístico. El altar mayor de las Descalzas Reales”, en Semanario Pintoresco Español, vol. I, n. ${ }^{\circ} 21$ (26 de mayo), Madrid, 1839, p. 161; TORMO Y MONZÓ, Elías, En las Descalzas Reales. Estudios Históricos, Iconográficos y Artísticos, vol. IV y último, Junta de Iconografía Nacional, Madrid, 1947, pp. 3637 , sobre el retablo mayor perdido; y pp. 38-44, sobre el dibujo de Becerra. 
la hornacina del ático se dedicaba al tema de la Resurrección bajo una bóveda de cuarto de esfera, con el asunto realizado en escultura al igual que los dos restantes de la misma calle principal, la Asunción y la Crucifixión ${ }^{51}$. Lucas Mitata conocía la obra, y es posible que también se dejara influir por Becerra a la hora de disponer los dos ángeles que rematan cada una de las calles laterales; los dibuja de perfil, de pie o genuflexos hacia la cruz que debía rematar el conjunto, lo mismo que en el citado grabado -y a diferencia de la traza-, donde se aprecia a dos Doctores de la Iglesia sentados en los laterales del ático mirando hacia el relieve central con la Resurrección. De igual suerte sucede con los dos angelitos sentados sobre el arranque de la cúpula placentina, y cuya relación con la angelología que Becerra desplegó en el retablo de la catedral de Astorga (contratado en 1558) es evidente, aunque no debemos descartar los modelos de la Escuela de Fontainebleau y del propio Juan de Juni.

La estancia madrileña de nuestro artista justifica la evolución de su estilo hacia la "introspección romanista" ${ }^{2}$, evidente en retablos como el mayor de la iglesia salamantina de Bañobárez (antes de 1583) o la cacereña de Descargamaría (1585-1594); sin embargo, y a diferencia de éstos, Mitata retomó en la traza placentina el protagonismo que ya le había concedido a la decoración manierista en obras como el citado retablo mayor de la parroquia salmantina de Fuenteguinaldo, ejecutado antes de $1575^{53}$.

En lo que respecta a la iconografía, el de Plasencia es el primer retablo dedicado a la Resurrección $^{54}$ dentro de la producción del escul-

TORMO Y MONZÓ, Elías, En las Descalzas Reales..., opus cit., p. 39.

52 REBOLLAR ANTÚNEZ, Alba, Lucas Mitata..., opus cit., p. 47.

53 Para las referencias de las obras citadas remitimos al trabajo de Rebollar Antúnez: ibídem, pp. 76-121 (Fuenteguinaldo), pp. 85-87 (Bañobárez) y pp. 87-91 (Descargamaría).

54 Las publicaciones de exégesis bíblica son literalmente inabarcables. Para una mirada suficiente sobre los textos de la Resurrección de Cristo que se citarán véase MARTÍN MORENO, Juan Manuel, "Los relatos de la resurrección según la exégesis y la teología actual", en Manresa. Revista de espiritualidad ignaciana, vol. LXXIX, n.o 311, Madrid, 2007, pp. 109-126; NOVO CID-FUENTES, Alfonso J., "El testimonio sobre la resurrección de Cristo en 1Cor 15", en Compostellanum. Revista de la archidiócesis de Santiago de Compostela, vol. LI, Santiago de Compostela, 2006, pp. 7-25; RI- tor. El sombreado de las hornacinas sugiere que todos los asuntos iban a ser ejecutados en escultura, lo que evidencia la filiación castellana de la traza. A la hora de analizar el programa iconográfico, debemos tener presente que no todos los detalles están claros; según señalábamos en la introducción, la humedad ha diluido especialmente la parte izquierda del dibujo, correspondiente al lado del evangelio; algunas figuras están mínimamente esbozadas con solo unos trazos, y las imágenes más elaboradas de los laterales carecen de atributos.

La predela consta de un total de nueve paneles. El más evidente es el central, con la representación de la sepultura de Cristo compuesta por varios personajes: dos hombres, uno por la cabeza y el otro por los pies, levantan el cadáver de Jesús amortajado mientras tres mujeres compungidas asisten al entierro desde el centro de la escena y por detrás del difunto. Es una imagen muy convencional de la sepultura de Cristo, aunque no se corresponde exactamente con los relatos evangélicos. Los cuatro evangelistas nos hablan de José de Arimatea (Mt 27,57; Mc 15,42; Lc 23,50; Jn 19,38), pero solo Juan $(19,39)$ nombra a Nicodemo; además solo los sinópticos citan a dos mujeres (Mt 27,61; Mc 15,47) o simplemente dicen "las mujeres" (Lc 23,55), sin precisar el número ${ }^{55}$. Sea como fuere, el panel central determina que muy probablemente la predela se pensaba ilustrar con escenas de la Pasión ordenadas de izquierda a derecha, ya que el último panel parece representar a Cristo Resucitado. Nos atrevemos a aventurar que la escena del tercer panel por el lado del evangelio representaría la unción de Jesús en Betania según la versión de San Juan (Jn 12,3).

El primer cuerpo del retablo alberga la escena con la Resurrección de Cristo ante el espanto de la guardia romana (Mt 28,2-4). El suceso así descrito no se apoya en ningún texto evangélico, puesto que en el relato de Mateo -el único que habla de los soldados romanos: Mt 27,6266-, Jesús no aparece, solo está el sepulcro vacío; cabe recordar que fue en el siglo XIV cuando se empezó a representar de tal modo la escena a consecuencia de la proyección que

DRUEJO ALONSO, Pedro, "La resurrección de Cristo", en La ciudad de Dios. Revista agustiniana, vol. CCXVIII, n. ${ }^{\circ}$ 2, El Escorial, 2005, pp. 301-334.

55 RÉAU, Louis, Iconografía del arte cristiano..., Nuevo Testamento, opus cit., pp. 542-544. 
tuvo sobre la misma el tema de la Ascensión ${ }^{56}$. Jesús, envuelto aún en la mortaja y con una vara de mando o cetro de autoridad en la mano izquierda, no levita, sino que está apoyado sobre la tapa del sepulcro, Christus supra sepulcrum, una imagen que los Padres de la Iglesia siempre interpretaron como la superación de la Antigua Alianza y fue recogida por los artistas desde el siglo XIII ${ }^{57}$. El terror de la guardia ante el suceso (Mt 28,4) se expresa con evidencia: en primer plano, uno de los soldados se refugia tras su escudo, otro se esconde rostro en tierra $\mathrm{y}$, tras el túmulo funerario, un tercero parece perderse corriendo ${ }^{58}$. La ausencia de atributos dificulta la identificación de los personajes situados en las hornacinas laterales; solo cabe destacar que parecen abatidos, con semblante triste y mirando al suelo: ¿Pedro y Juan que hasta no ver el sepulcro vacío no creyeron en la Resurrección de Cristo (Jn 20,8-9)?

El segundo cuerpo está centrado en una escultura de la Ascensión de Cristo. Se trata claramente de un asunto escultórico porque Jesús tiene los brazos abiertos y Mitata ha pintado las manos sobresaliendo de la hornacina y por detrás de las columnas. Esa apertura de los brazos también nos da la clave para identificar el momento de la ascensión según el relato evangélico (Lc 24,50-51) ${ }^{59}$. Este Cristo es el único personaje del retablo que tiene aureola, aunque pintada de una manera un tanto extraña, de lado, quizá para remarcar el eje oblicuo de su cabeza. Las figuras situadas en las hornacinas laterales carecen de atributo, aunque, de nuevo, tienen la mirada baja, hacia el suelo, y uno -el del lado de la epístola- tiene el cuerpo girado, casi dando la espalda: ¿Pablo que de perseguidor pasó a apóstol (Hch 9,4-6; 1Cor 15,8) y To-

$56 \quad$ Ibidem, p. 566.

57 BALDERAS VEGA, Gonzalo, Cristianismo, sociedad y cultura en la Edad Media. Una visión contextual, Universidad Iberoamericana, México, 2008, p. 502.

58 Por cierto, la explicación que ofrece Mt 28,11-15 cuando las autoridades judías defendieron a los soldados romanos frente a sus superiores tras desaparecer el cadáver de Jesús, es inverosímil. Tal negligencia se pagaba con la vida: PITILLAS SALAÑER, Eduardo, "Los soldados del ejército romano durante la etapa del alto imperio. Sus componentes más básicos: el ciudadano-soldado (legionario) y el soldado auxiliar", en Millars. Espai i historia, vol. XLIII, n. ${ }^{\circ}$ 2, Castellón de la Plana, 2017, pp. 72, 79. Sobre la iconografía descrita véase también la obra de RÉAU, Louis, Iconografía del arte cristiano..., Nuevo Testamento, opus cit., p. 572.

59 RÉAU, Louis, Iconografía del arte cristiano..., Nuevo Testamento, opus cit., p. 606. más el incrédulo (Jn 20,25)? Sea como fuere, su riqueza iconográfica es notable.

La iconografía del segundo nivel del retablo termina con las dos figuras situadas sobre el cornisamento del primer cuerpo, a plomo con las columnas más extremas. Aún es visible la que va situada en la epístola, no así la del evangelio, que se ha perdido por la humedad. Según hemos visto, dicha figura es muy similar a la que va situada en el mismo sitio del retablo catedralicio de Burgo de Osma, aunque en nuestro caso se trata de una representación masculina ataviada con túnica y, acaso, con la piel de camello alusiva al Bautista, precursor inmediato de Cristo, cuya misión fue la de revelar al Mesías en la persona de Jesús (Jn 1,15.30). Es posible que estuviera acompañado en el evangelio por la figura de Isaac, es decir, el hijo de la promesa (Gál 4,22-28), precursor de Cristo y de la Iglesia, cuyo sacrificio, aunque no consumado, le asimila al Salvador ${ }^{60}$ e identifica con él (Gál 3,16). Estaríamos, pues, ante dos alusiones al Antiguo y Nuevo Testamento, o lo que es lo mismo, la preparación del camino a Jesús, y la revelación y explicación de quién es: el tránsito de la Antigua a la Nueva Alianza. El carácter simbólico de ambas figuras queda subrayado al ir situadas sobre las columnas más extremas, enmarcando la venida y salvación de Cristo.

La angelología puebla el ático y culmina el todo, mirando y señalando hacia la cruz que debía ir proyectada sobre la peana situada en la clave de la cúpula.

\section{Y un último apunte a modo de conclusión}

El retablo que Lucas Mitata proyectó hacia 1592 finalmente no se llevó a cabo, lo que, a la postre, permitió insistir en el culto a las reliquias con la construcción de los dos relicarios que el obispo Dávila y Toledo (1622-1625) mandó ubicar en los brazos del crucero, según hemos visto. De todo el programa iconográfico que se ideó con Ochoa y Salazar al frente de la silla episcopal, solo se hizo la escultura de la Virgen del Tránsito dada su importancia para la catedral. Aunque se había decidido encargar una nueva talla en 1588, su llegada a la ciudad se dilató hasta el año siguiente del viaje

\footnotetext{
60 Íd., Iconografía del arte cristiano. Iconografía de la Biblia, t. 1, vol. 1, Antiguo Testamento, Ediciones del Serbal, Madrid, 1996 [1956리, p. 170.
} 
que Lucas Mitata hizo a Plasencia en 1592. No sería desacertado pensar que a él se le hubiera encomendado también la ejecución de la escultura. Sin embargo, no hemos podido analizar la obra debido al difícil acceso que presenta, al estar situada en una urna dentro del retablo que hicieron los hermanos Churriguera; nuestra idea no deja de ser, por tanto, una hipótesis de trabajo. Sabemos que se trata de una escultura vestidera que no está tallada en su conjunto, tan solo la cabeza y las manos, además de los brazos y el tronco, no así las piernas ${ }^{61}$. El capellán de la catedral de Plasencia José María Barrio y Rufo (1803-1880) recogía en 1851 el dato sobre la procedencia salmantina de la talla ${ }^{62}$, al igual que hizo el chantre José Benavides Checa
(1844-1912) en $1907^{63}$. Aunque no hemos localizado el asiento del que procede esta referencia, lo cierto es que Mitata estaba avecindado en Ciudad Rodrigo desde 1563, localidad desde la que atendía los diversos encargos que llegaban a su taller ${ }^{64}$. De corroborarse nuestra hipótesis, estaríamos ante la primera escultura mariana exenta conservada dentro de la producción del escultor, quien, además, contaba con una larga experiencia en la talla de figuras yacentes gracias a los sepulcros que había contratado a lo largo de su trayectoria, entre los que destaca el entierro que hizo para el comendador alcantarino D. Diego Bravo de Jerez entre 1560 y 1562, hoy conservado en la iglesia parroquial de Santa María de Almocóvar, Alcántara (Cáceres) ${ }^{65}$.

61 La obra es muy similar, en cuanto a las zonas que presenta trabajadas, a los ejemplos que recoge Cea Gutiérrez de esculturas vestideras de la Virgen del Tránsito, aunque las obras que cita corresponden al siglo XIX: CEA GUTIÉRREZ, Antonio, Religiosidad popular. Imágenes vestideras, Obra Cultural de Caja España, Zamora, 1992, pp. 142-143.

62 BARRIO Y RUFO, José Ma , Apuntes para la Historia General de la M.N. y M.L. ciudad de Plasencia de Estremadura, Imprenta de D. Manuel Ramos, Plasencia, 1851, p. 54.

63 BENAVIDES CHECA, José, Prelados placentinos..., opus cit., p. 201.

64 PÍRIZ PÉREZ, Emilio, El escultor Lucas Mitata, opus cit., p. 237.

65 MARTÍN NIETO, Dionisio, Luis de Morales y Lucas Mitata..., opus cit., pp. 55-60. 